Investments (par value $\$ 8,500.00$ ) $\ldots \ldots \ldots \ldots . \$ 8,259.50$

Balance in First National Bank (Ithaca) ...... 1,205.78

Balance in Ithaca Savings Bank .......... $500.00 \quad 9,965.28$

The Life Membership Fund now amounts to $\$ 6,843.46$.

\title{
J. H. TANNER,
}

Treasurer.

ITHACA, N. Y.,

December 20, 1918.

REPORT OF THE AUDITING COMMITTEE.

The undersigned Auditing Committee, appointed by the American Mathematical Society, have this day examined the accounts of the Treasurer, compared them with the vouchers, bank books, and securities, and find the following to be correct:

Balance from December 20, $1917 \ldots \ldots \ldots \ldots \ldots \ldots \ldots \ldots . \$ 99,762.98$

Cash receipts since December $20,1917 \ldots \ldots \ldots \ldots \ldots \ldots$. $5,911.86$

Balance in First National Bank (Ithaca) ..... $\$ 1,205.78$

Balance in Ithaca Savings Bank ........... 500.00

Investments (par value $\$ 8,500.00$ ) $\ldots \ldots \ldots \ldots .8,259.50$

Disbursements since December 20, $1917 \ldots \ldots \ldots .5,709.56$

$\overline{\$ 15,674.84}$

JOSEPH G. COFFIN, Charles C. Grove,

NEW YoRK, N. Y., Auditing Committee.

December 20, 1918. 